Edited by:

Kenneth Hugdahl, University of Bergen, Norway

Reviewed by:

Nils I. Landro, University of Oslo,

Norway

Kenneth Hugdahl, University of Bergen,

Norway

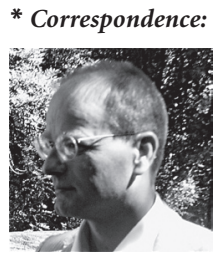

Ulman Lindenberger is the Director of the Center for Lifespan Psychology at the Max Planck Institute for Human Development, Berlin. He received his doctoral degree in psychology from the Free University Berlin in 1990. Ulman Lindenberger is a member of the German Academy of Sciences Leopoldina, and holds honorary professorships at the Free University, Berlin, Humboldt University, Berlin, and Saarland University,

Saarbrücken. His primary research interests concern cognitive and brain plasticity across the entire lifespan, dependencies between sensorimotor and cognitive aging, and multivariate developmental methodology. lindenberger@mpib-berlin.mpg.de

\title{
Age-related decline in brain resources modulates genetic effects on cognitive functioning
}

\author{
Ulman Lindenberger ${ }^{*}$, Irene E. Nagel ${ }^{1}$, Christian Chicherio ${ }^{1,2}$, Shu-Chen Li ${ }^{1}$, \\ Hauke R. Heekeren ${ }^{1,3}$ and Lars Bäckman ${ }^{1,4 *}$ \\ 1 Max Planck Institute for Human Development, Berlin, Germany \\ 2 Faculty of Psychology and Educational Sciences, University of Geneva, Geneva, Switzerland \\ ${ }^{3}$ Max Planck Institute for Human Cognitive and Brain Sciences, Leipzig, Germany \\ ${ }_{4}^{4}$ Aging Research Center, Karolinska Institute, Stockholm, Sweden
}

Individual differences in cognitive performance increase from early to late adulthood, likely reflecting influences of a multitude of factors. We hypothesize that losses in neurochemical and anatomical brain resources in normal aging modulate the effects of common genetic variations on cognitive functioning. Our hypothesis is based on the assumption that the function relating brain resources to cognition is nonlinear, so that genetic differences exert increasingly large effects on cognition as resources recede from high to medium levels in the course of aging. Direct empirical support for this hypothesis comes from a study by Nagel et al. (2008), who reported that the effects of the Catechol-O-Methyltransferase (COMT) gene on cognitive performance are magnified in old age and interacted with the Brain-Derived Neurotrophic Factor (BDNF) gene. We conclude that common genetic polymorphisms contribute to the increasing heterogeneity of cognitive functioning in old age. Extensions of the hypothesis to other polymorphisms are discussed. (150 of 150 words)

Keywords: genes, aging, resources, cognition, dopamine

\section{INTRODUCTION}

Cognitive aging is marked by heterogeneity: Older adults who preserve high levels of cognitive functioning into very old age stand in sharp contrast to age peers whose cognitive resources are waning by the time they reach later adulthood (Bäckman et al., 1999). Longitudinal studies confirm that individual differences in cognitive performance increase from early to late adulthood (e.g., de Frias et al., 2007), and suggest that both genetic and environmental factors contribute (Finkel et al., 2005). This increasing cognitive heterogeneity in aging likely stems from a multitude of factors, an obvious category being disease (e.g., the presence or absence of dementia and old-age depression). Here, we focus on another potential determi- nant of increased between-person differences in late-life cognition: That losses of brain resources associated with normal aging amplify the effect of common genetic polymorphisms on human cognition, thereby contributing to the observed increase in heterogeneity.

Normal cognitive aging is associated with a general loss of resources (Craik, 1983; Kinsbourne and Hicks, 1978). At the neurochemical level, the continuous decline of striatal and extrastriatal dopamine (DA) systems from early to late adulthood and old age is particularly important (Bäckman et al., 2000, 2006; Erixon-Lindroth et al., 2005; Volkow et al., 1998). Molecular imaging studies indicate that age-related DA losses are powerful mediators of age-related 


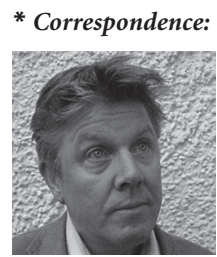

Lars Bäckman is professor of psychology and Director at the Aging Research Center, Karolinska Institutet, Stockholm He received his doctoral degree in psychology from the University of Umea Sweden in 1984. Lars Bäckman is a member of the Royal Swedish Academy of Sciences and the European Academy. His primary scientific interests concern cognitive functioning in normal and pathological aging, with special focus on memory. Current research themes include the transition from normal aging to dementia, the role of dopamine functions in cognitive aging, and cognitive and brain plasticity in adulthood and old age. lars.backman.1@ki.se impairment in multiple cognitive tasks, including those assessing WM, executive functions, and episodic memory (see Bäckman et al., 2006, for review).Anatomically, reductions in white-matter integrity and volume are particularly pronounced in prefrontal and medio-temporal areas of the brain (e.g., Raz et al., 2005, 2008b). Accordingly, normal human aging is associated with decline across a wide range of sensory, perceptual, and cognitive abilities (Baltes and Lindenberger, 1997). Higher-order cognitive functions that rely on the integrity of the prefrontal cortex (PFC) and the medial-temporal lobes (MTL), such as executive functions, working memory (WM), and episodic memory, show particularly pronounced normative age-related decline (Bäckman et al., 1999; Brehmer et al., 2007; Shing et al., 2008; West, 1996).

Individual differences in complex phenotypes such as cognition result from gene-gene and genecontext interactions (Baltes et al., 1999; Diamond, 2007; Li, 2003; McClearn, 2006; Posner et al., 2007; Reynolds et al., 2007). Twin studies indicate that individual differences in human cognition are closely linked to genetic variability (McClearn et al., 1997; McGue et al., 1993). In normal populations, more than $60 \%$ of individual differences in cognitive abilities are heritable, including reliability-adjusted measures of fluid intelligence, WM, and executive functioning (Friedman et al., 2008). Furthermore, individual differences in cognition are remarkably stable across the adult lifespan (Deary et al., 2004; Hertzog and Schaie, 1986), suggesting a powerful synergy between genetic and environmental conditions (Baltes et al., 1999). For instance, Hertzog and Schaie (1986) found that 7-year stability coefficients for a composite of general cognitive ability ranged from 0.89 to 0.96 in samples with mean ages between 25 and 67 years at first testing, indicating a substantial degree of stability of individual differences. Finally, twin studies suggest that individual differences in the acceleration of cognitive decline from adulthood to old age are strongly influenced by genetic factors (Finkel et al., 2005).

Advances in molecular genetics make it possible to identify specific genes affecting brain chemistry, structure, and function, as well as associated cognitive functions in humans (Goldberg and Weinberger, 2004). At present, close to 100 candidate genes influencing human brain functions and cognition have been reported (e.g., de Geus et al., 2008). Any given gene is likely to affect more than one cognitive function, and variations in any given cognitive function are likely to be influenced by more than one gene. For example, the brain circuitries implementing WM and epi- sodic memory show considerable overlap, and the proteins coded by different genes are generally active in more than one brain region. Therefore, recent publications stress the need to consider gene-gene interactions (de Geus et al., 2008; Kovas and Plomin, 2006; Tan et al., 2007; Yacubian et al., 2007). Despite (or perhaps because of) these complications, the identification of cognitively relevant genes bears the promise to refine and constrain our knowledge about neurobiological mechanisms in human cognition, including its age-graded changes, especially if the physiological effects of the respective gene are reasonably well understood.

\section{RESOURCE MODULATION OF GENETIC INFLUENCE: A HYPOTHESIS}

As summarized above, human cognition in adulthood and old age is characterized by two features: (1) normative decline in neurochemical, anatomi$\mathrm{cal}$, and functional brain resources, with resulting impairments in the mechanisms supporting executive functioning, WM, and episodic memory; and (2) a high degree of heritability and stability of individual differences in cognitive functioning, at least up to the eighth decade of life.

Based on these two observations, we put forward the hypothesis that losses in neurochemical and structural brain resources associated with normal aging modulate the extent to which common genetic variations affect cognitive functioning. Specifically, we expect that the effects of genetic polymorphisms on cognitive performance should be magnified in late relative to early adulthood. Our hypothesis rests on the assumption that the function relating brain resources to cognitive performance is nonlinear, so that genetic variability is more likely to result in performance differences when resources move away from close-to-optimal levels, as in normal aging (see Figure 1).

The postulated non-linear shape of the resource-performance relationship, with a steeper slope in the middle of the function, is consistent with item response theory and empirical data. In item response theory, the item-characteristic curve denotes the probability that a person with a given level of resources will respond correctly (Lord, 1980; Mellenbergh, 1994). By definition, almost everybody solves easy items, and only few solve difficult items. Items of medium difficulty are solved by about half the population, and therefore discriminate best between individuals. This property is captured by Figure 1, where the slope of the function relating resources to performance is steepest at the medium resource level. As normal aging moves individuals' resources 


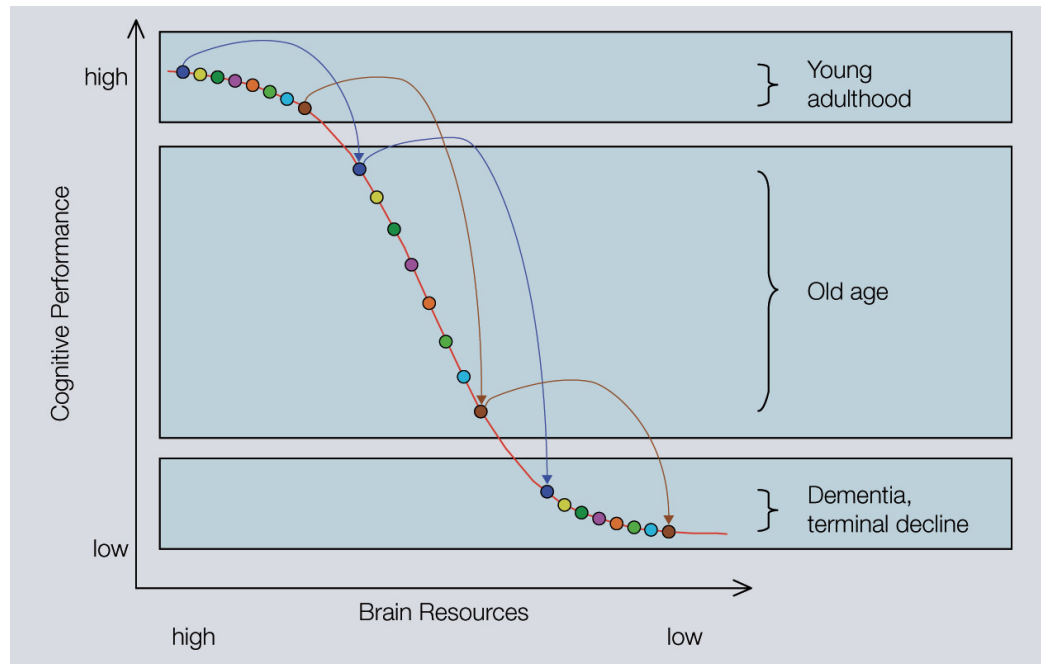

Figure 1 | The resource modulation hypothesis posits that losses in chemical and structural brain resources associated with normal aging modulate the effects of common genetic variation on cognitive performance. As normal aging moves individuals' resources from the top to the middle portion of the resource function, constant amounts of genetic variation are translated into increasingly larger performance differences. With depleted resources, genetic effects are expected to dwindle again. The colored circles represent eight individuals with different combinations of genetic polymorphisms as they move from early adulthood over old age to dementia or terminal decline. port and are able to profit from it. By analogy, performance-enhancing allelic variants can be construed as a form of "genetic support." It follows that their leverage on cognition should be greatest at intermediate resource levels.

\section{COMT AND BDNF GENE EFFECTS ON EXECUTIVE FUNCTIONING AND WORKING MEMORY IN YOUNGER AND OLDER ADULTS}

Among the numerous genes that have been identified as affecting human cognition, the Catechol-O-Methyltransferase (COMT) gene, implicated in executive functions and WM, and the Brain-Derived Neurotrophic Factor (BDNF) gene, associated with memory-related functions, have received much attention (e.g., Goldberg and Weinberger, 2004; Savitz et al., 2006). Recently, Nagel et al. (2008) examined the effects of the COMT and BDNF genes on executive functioning and spatial WM performance in younger and older adults. The rationale and results of this study are directly pertinent to the resource modulation hypothesis, and are reported in detail below.

COMT enzymatic activity results in degradation of DA and thus influences endogenous DA levels in PFC. A common polymorphism of the COMT gene is associated with variation in intrinsic prefrontal DA levels. The COMT single nucleotide polymorphism leads to a substitution of valine (Val) with methionine (Met) at the codon 158 on chromosome 22q11 (Val158Met). This substitution affects enzymatic activity, which is three to four times higher in Val than in Met homozygotes. Lower enzymatic activity among Met carriers leads to less frontal DA degradation, and hence greater DA availability at the receptors (Meyer-Lindenberg et al., 2007).

Some behavioral studies using tasks that tax executive functioning, such as the Wisconsin Card Sorting Test (WCST), or working memory tasks, such as n-back, have found an advantage of Met over Val carriers among younger adults. However, effect sizes are generally small (Egan et al., 2001; Malhotra et al., 2002; Meyer-Lindenberg et al., 2006) and not always statistically reliable (Barnett et al., 2007). One reason for the relatively small effects may be that the advantage of Met carriers in executively demanding tasks applies to sustained processes such as maintaining a cognitive set, but not to transient processes related to cognitive flexibility (Bilder et al., 2004; Grace et al., 2007).

Animal and human data suggest that the relation between DA levels and cognitive functioning follows an inverted U-shaped function (GoldmanRakic et al., 2000; Li and Sikström, 2002; Li et al., 2001; Mattay et al., 2003; Vijayraghavan 
et al., 2007). The DA system undergoes marked decline across the adult life span, with a gradual loss of both pre- and post-synaptic markers of DA neurotransmission from early through late adulthood (Antonini and Leenders, 1993; Erixon-Lindroth et al., 2005; Kaasinen et al., 2000; Suhara et al., 1991). This loss is consistently found in striatal, neocortical (e.g., frontal), and limbic areas (Bäckman et al., 2006). Given the close association between deficient dopaminergic neuromodulation and age-related cognitive decline (Bäckman et al., 2006), it is plausible to assume that advancing adult age shifts individuals toward the left-hand portion of the curve relating DA signaling to cognitive performance, that is, further and further away from the functional optimum. The deleterious effects of this leftward shift should be particularly pronounced among individuals with relatively low DA levels in young adulthood, such as Val carriers of the COMT gene. Therefore, Nagel et al. (2008) predicted that the loss of cognitive resources associated with normal human aging would magnify the effects of the COMT polymorphism on executive functioning and WM (Figure 2). Note that the logic behind this prediction is a mechanistic instantiation of the more general hypothesis that lower levels of cognitive resources are associated with lower performance and greater genetically-induced variability in behavior.

Thus far, most studies investigating COMT effects on cognitive performance have involved younger adults. However, in line with our hypothesis, the few studies on older adults consistently reported a clear advantage of Met over Val carri-

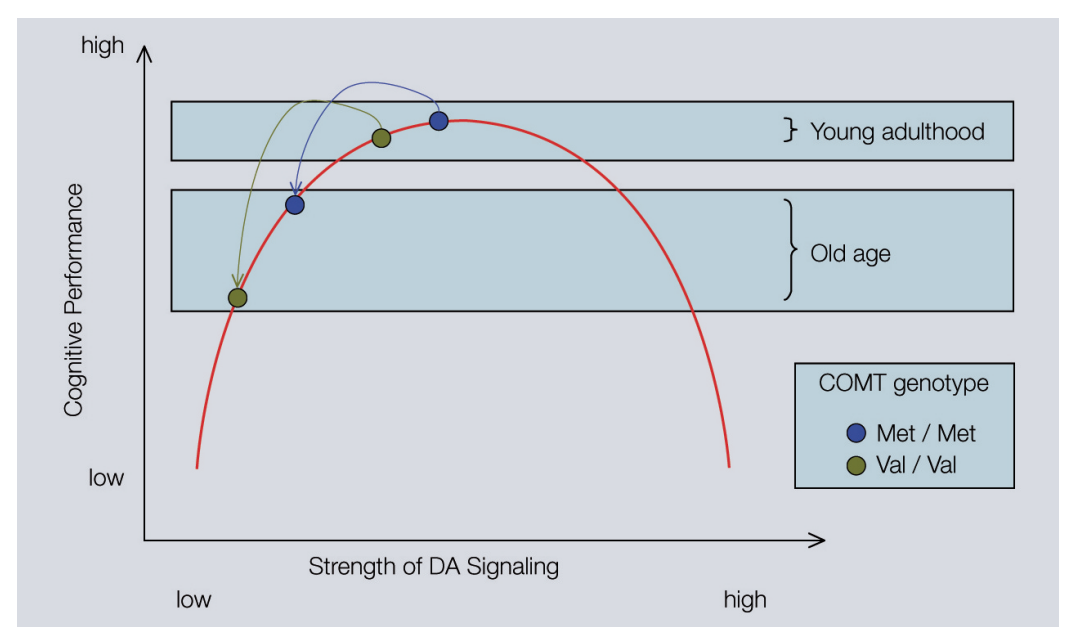

Figure 2 | Function relating the strength of frontal DA signaling to cognitive performance. The inverted $U$ shape of the curve implies that performance differences between Met and Val carriers of the COMT gene are greater for older adults than for younger adults, reflecting the decline in dopaminergic neuromodulation with advancing adult age. ers on tasks assessing WM and related cognitive functions (de Frias et al., 2004, 2005; Harris et al., 2005; Mattay et al., 2006; Starr et al., 2007). Studies on gene-gene interactions involving COMT have focused on interdependencies between the COMT gene and other genes linked to the catecholaminergic system, such as the DA transporter gene (Yacubian et al., 2007), the serotonin transporter gene 5-HTTLPR (Smolka et al., 2007), and the DA D2 receptor gene DRD2 (Gosso et al., 2008). In contrast, Nagel et al. (2008) focused on the interaction between the COMT gene and the common $\mathrm{Val} / \mathrm{Met}$ polymorphism affecting the BDNF protein, which enhances MTL-related mechanisms such as long-term potentiation and associative binding (Egan et al., 2003). Secretion of BDNF is higher in Val homozygotes than in Met carriers. BDNF Val homozygotes also have greater hippocampal volume and task-related brain activation, as well as higher performance in memory tasks than Met carriers (Egan et al., 2003; Hariri et al., 2003; Pezawas et al., 2004).

The influence of BDNF on brain and cognition is not restricted to MTL-dependent memory processes. Met carriers show reduced grey-matter volume in prefrontal cortex (Xu et al., 2007) and perform less well on the WCST (Rybakowski et al., 2003). Furthermore, BDNF influences DA release in striatal regions (Narita et al., 2003), which may interact with COMT effects on prefrontal DA catabolism through basal ganglia-thalamocortical loops (Alexander et al., 1986). Thus, for several reasons, Nagel et al. (2008) predicted that the COMT and BDNF genes would interactively influence executive functioning and WM. First, PFC and MTL are strongly connected and co-activated during a wide range of executive tasks (Cabeza et al., 2003; Courtney et al., 1997; Rypma and D'Esposito, 2000). Second, although COMT has primarily been associated with PFC (Meyer-Lindenberg et al., 2007), and BDNF with MTL (Hariri et al., 2003), both genes influence both brain regions (Bertolino et al., 2006; Pezawas et al., 2004). Therefore, Nagel et al. (2008) also examined whether age differences in the effects of the COMT Val/Met polymorphism on executive functioning and WM are modulated by the Val/ Met BDNF polymorphism.

In sum, the key prediction by Nagel et al. (2008) was that human aging magnifies the functional consequences of genetic variations affecting DA signaling (Figure 2). This prediction was derived from inverted U-shaped relation of DA activity to cognitive performance, and the important role of deficient dopaminergic neuromodulation in cognitive aging. Further, given the role of BDNF in frontal integrity (Pezawas et al., 2004) 
and the role of the MTL in executive functioning (Courtney et al., 1997; Takahashi et al., 2007), Nagel et al. (2008) also predicted that the relation between COMT status and adult age would be modulated by BDNF genotype. Specifically, Nagel et al. (2008) expected that older COMT Val carriers who also carry the Met allele of the BDNF gene would show particularly low levels of executive performance.

To test these predictions, 164 younger adults aged 20-31 years and 154 older adults aged 60-70 years were assessed on the WCST and a spatial WM task. A computer-administered adapted version of the standard 128-cards WCST was used (Heaton et al., 1993), and participants were instructed to perform as fast and accurately as possible. Performance was evaluated by applying the WCST standard scoring rules, as described by Heaton et al. (1993). The percentage of perseverative errors and reaction times for correct responses were used to index performance. In the spatial WM task, participants were visually presented with a series of dots, displayed consecutively in a specific location in a $4 \times 4$ grid of circles. Load level was manipulated by the number of dots in the sequence (i.e., four or seven). DNA was extracted from peripheral blood, and analyzed using standard methods (for details, see Nagel et al., 2008). The allelic distributions of both genes did not deviate significantly from those expected according to Hardy-Weinberg equilibrium in either age group.

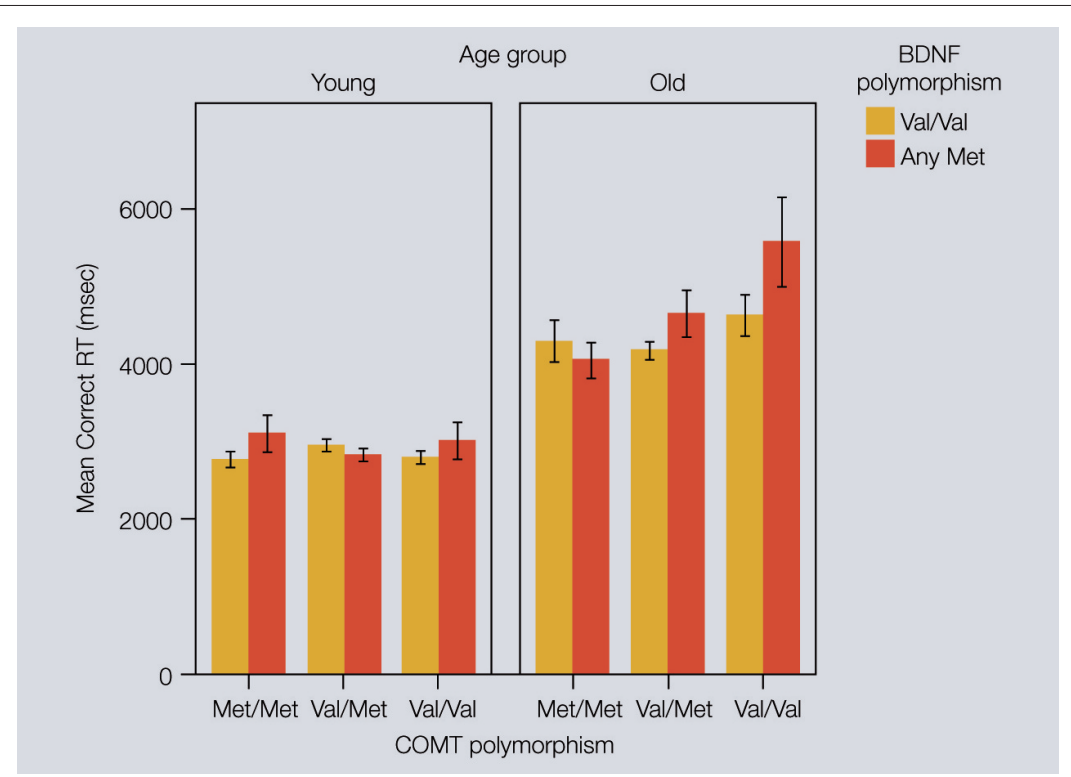

Figure 3 | Results from Nagel et al. (2008). Mean reaction time for correct WCST responses as a function of age, COMT genotype, and BDNF genotype. The age $\times$ COMT interaction accounted for $4.1 \%$, and the age $\times$ COMT $\times$ BDNF interaction for $3.1 \%$ of the variance.
The data obtained on the two tasks were consistent with both predictions. First, for the WCST, the COMT Val allele was associated with a higher number of perseverative errors in older, but not in younger, adults. In addition, reaction times for correct responses on the WCST were also dependent on BDNF status: Older adults carrying two COMT Val alleles and at least one BDNF Met allele took a particularly long time to respond, resulting in an age $\times$ gene $\times$ gene interaction (see Figure 3 ). Second, for the spatial WM task, genetic modulation of performance was restricted to reaction times for correct responses. In the low-load condition (set size 4), COMT effects on processing efficiency were not reliable in younger adults, but present in older adults. This age $\times$ gene interaction pattern closely resembled that found for perseverative errors in the WCST. In the high-load condition (set size 7), Nagel et al. (2008) again observed a triple interaction of age, COMT, and BDNF. In line with expectations, response times were particularly slow in older adults carrying two COMT Val alleles and at least one BDNF Met allele. This pattern mirrors the WCST latency data for correct responses.

The results from both tasks support the notion that effects of the Val/Met COMT polymorphism on executive functioning and WM increase in old age, and are further accentuated by the corresponding BDNF polymorphism. The observed age $\times$ gene and age $\times$ gene $\times$ gene interactions explained between $2.3 \%$ and $4.1 \%$ of the total variance in the cognitive variables.

Most investigations on cognitive effects of the COMT gene have included younger adults (Bilder et al., 2004; Egan et al., 2001; Ho et al., 2005; Mattay et al., 2003; Montague et al., 2004). It may seem surprising that Nagel et al. (2008) did not observe reliable COMT effects in younger adults, as such effects have been observed in earlier studies with smaller samples (Egan et al., 2001; Mattay et al., 2003; Montague et al., 2004). As noted, however, the evidence on COMT effects on executive functioning and WM in early adulthood is not unequivocal, for several studies have failed to find such effects (Barnett et al., 2007; Bilder et al., 2004; Ho et al., 2005; Tsai et al., 2003). In contrast, the few cognitive studies with older adults have invariably reported COMT effects in the expected direction (de Frias et al., 2004, 2005; Harris et al., 2005; Mattay et al., 2006; Starr et al., 2007). The direct age-comparative evidence obtained in this study provides novel support for the view that COMT effects are unmasked in old age, presumably because older adults are operating at suboptimal levels of dopaminergic neuromodulation. 
Based on animal research, molecular imaging studies in humans, and neurocomputational modeling, Nagel et al. (2008) assumed that agerelated decline in DA signaling leads to noisier and less efficient processing in PFC (Bäckman et al., 2006; Li et al., 2001). DA signaling is known to affect PFC-related cognitive functions in an inverted U-shaped manner (Goldman-Rakic et al., 2000; Li and Sikström, 2002; Mattay et al., 2003; Vijayraghavan et al., 2007). Nagel et al. (2008) also assumed that normal aging moves individuals further to the left on the inverted U-shaped curve, and that Val COMT carriers start this lifespan shift further to the left than Met COMT carriers. As a result, it follows that Val COMT carriers undergo a greater loss of DA signaling than Met carriers (see Figure 2). The results are in excellent agreement with this model, thereby extending the validity of the inverted-U shaped function to normal human aging. At the same time, the results by Nagel et al. (2008) also match the general expectation that normal aging modulates the behavioral consequences of genetic variability (see Figure 1).

Finally, Nagel et al. (2008) also found that the BDNF gene modulates the interaction between age and COMT status. There is evidence that carriers of the BDNF Met allele perform more poorly in tasks assessing memory and fluid intelligence than Val carriers (Egan et al., 2003; Hariri et al., 2003; Ho et al., 2006; Tsai et al., 2004). Nagel et al. (2008) found that older Met BDNF carriers took more time to respond in the WSCT and in the high-load condition of the spatial WM task if they were Val homozygotes on the COMT gene. The resulting triple interaction among age, COMT, and BDNF, in which BDNF further exacerbated the processing disadvantage of older individuals who are Val homozygotes on COMT, lends further support to the view that COMT and BDNF are jointly involved in regulating the PFC-MTL/ executive control-episodic memory circuitry (Buckner et al., 1996; Miller and Cohen, 2001). The influence of BDNF on this circuitry may have at least three origins. Anatomically, BDNF affects both PFC and hippocampal gray-matter volumes (Pezawas et al., 2004). Neurochemically, BDNF influences DA release in striatal regions (Narita et al., 2003) that may affect PFC functions through the striato-thalamo-cortical pathway (Alexander et al., 1986). Functionally, the MTL and the PFC jointly contribute to executive functioning, WM, and episodic memory circuitries (Naghavi and Nyberg, 2005). For instance, a recent study showed that DA $\mathrm{D}_{2}$ receptor binding potential in MTL is strongly related to WCST performance (Takahashi et al., 2007). Similarly, patient studies show that various forms of MTL damage affect WM in addition to episodic memory (Olson et al., 2006; Piekema et al., 2007).

The results reported by Nagel et al. (2008) are novel in two ways. First, the age-associated magnification of COMT gene effects provides new evidence in support of the inverted U-shaped relation between dopaminergic neuromodulation in PFC and cognitive performance (but see Raz et al., in press). Second, the modulation of COMT gene effects by the BDNF gene extends recent evidence of close interactions between frontal and MTL circuitries in executive functioning and WM. Taken together, the results are consistent with our hypothesis that resource losses in normal aging magnify the effect of common genetic variations on human cognition.

\section{FURTHER TESTS OF THE RESOURCE MODULATION HYPOTHESIS}

In this article, we advance the hypothesis that normal aging modulates genetic effects on human cognition (see Figure 1), and reviewed initial evidence by Nagel et al. (2008) supporting this hypothesis. The Nagel et al. (2008) study was restricted to two genes, COMT and BDNF, and their effects on executive functioning and spatial WM. Obviously, the results reported by Nagel et al. (2008) need to be replicated, and the resource modulation hypothesis should be tested in additional cognitive domains, and with a larger array of candidate genes as well as their interactions. Here, we will not attempt to provide a comprehensive overview of candidate genes and cognitive domains (for summaries, see de Geus et al., 2008; Mattay et al., 2008). Rather, to complement the focus of Nagel et al. (2008) on executive functioning and WM, we will selectively focus on four genes that are particularly relevant for episodic memory, namely GRM3, BDNF, KIBRA, and APOE.

In addition to DA, working memory functioning is critically dependent upon glutamatergic and GABAergic systems (Seamans and Yang, 2004). Therefore, we expect that the effects of genes regulating the expression of glutamate and GABA on working memory should increase with advancing age, and interact with the COMT gene. To our knowledge, age-comparative evidence testing this prediction is not yet available. In a study with young adults, Tan et al. (2007) recently reported interactive effects of the COMT gene and the type II metabotropic glutamate receptor 3 (GRM3) gene on the engagement of prefrontal cortex during working memory performance. The GRM3 genotype, putatively associated with suboptimal glutamatergic signaling, was associ- 
ated with inefficient prefrontal engagement and altered prefrontal-parietal coupling in COMT Val homozygotes, whereas GRM3 gene effects were less pronounced in COMT Met homozygotes. If we conceive of variations in the COMT gene as a resource manipulation, with Val homozygotes being lower in working memory-related prefrontal resources than Met homozygotes, then the greater effect of GRM3 in COMT Val homozygotes is consistent with the resource modulation hypothesis. We expect that advancing adult age will further enhance the epistatic interaction between COMT and GRM3.

Following up on the findings reported by Nagel et al. (2008), future research also needs to examine whether the effects of the BNDF gene also increase with advancing adult age in the domain of episodic memory. In Nagel et al. (2008), the BDNF gene effects on executive functioning and WM were confined to old COMT Val/Val carriers. In the other age and COMT groupings, the effect of the BDNF gene was negligible. In view of the robust BDNF gene effects on episodic memory (Egan et al., 2003; Hariri et al., 2003; Ho et al., 2006), we predict that the BDNF Val advantage in episodic memory is exacerbated in old age. So far, most studies on BDNF gene effects on cognition were confined to one age group (but see Raz et al., 2008a), and did not allow for a direct test of age $\times$ gene interactions. Recently, Miyajima et al. (2008) found a reliable BDNF Val advantage on tests of delayed recall, processing speed, and a general intelligence factor in a sample of 722 adults aged $50-85$ years. Relative to homozygous Val individuals, heterozygous and homozygous Met individuals scored 3\% and 13\% lower on the delayed recall test, respectively. In a sample of 103 healthy adults aged 19-77 years, Raz et al. (2008a) found that elevated levels of fasting blood glucose, included in the study as an indicator of vascular risk, was associated with lower memory scores only in carriers of the BDNF Met allele. Given that elevated blood glucose levels are more prevalent at older ages (for review, see Morley, 2008), and accompanied by losses in cognitive resources (e.g., Huber, 2008; Rolandsson et al., 2008), this finding fits the general scenario depicted in Figure 1.

Papassotiropoulos et al. (2006) recently discovered the role of the KIBRA gene in episodic memory. These authors performed a hypothesis-free whole genome wide association scan, covering more than 500,000 single nucleotide polymorphisms (SNPs) to identify genes linked to episodic memory performance. The strongest association was observed for the rs17070145 SNP, which is a common $\mathrm{T} \rightarrow \mathrm{C}$ exchange within the ninth intron of the KIBRA gene. KIBRA encodes a protein that interacts with protein kinase $\mathrm{C}$ and probably plays a role in synaptic plasticity and memory formation (Buther et al., 2004). In three independent young and middle-aged samples, CC carriers performed less well on verbal and visual episodic memory tasks than CT and TT carriers. Schaper et al. (2008) replicated these results in a small sample of healthy older adults, using the German version of the Rey Auditory Verbal Learning test as a measure of episodic memory. In this study, the effect sizes for the KIBRA gene were at least as large or larger than those reported by Papassotiropoulos et al. (2006). Again, direct age comparisons with identical measures would be needed to test whether KIBRA gene effects on memory increase from early to late adulthood.

The apolipoprotein E gene (APOE) is the most clearly established genetic risk factor for Alzheimer's disease (AD). It codes for apolipoprotein $\mathrm{E}$, the primary cholesterol transporter in the brain, which, among other things, is implicated in brain repair mechanisms. The APOE gene has three alleles, e2, e3, and e4, the most common being e3. Negative effects of the e 4 allele on cognition are generally absent in young adults (e.g., Alexander et al., 2007; Schultz et al., 2008), but the e4 disadvantage is present in healthy older adults for episodic memory and executive functioning (e.g., Deary et al., 2002; Small et al., 2004). Compared to non-e4 carriers, AD risk is significantly increased for people with genotypes $\mathrm{e} 2 / \mathrm{e} 4$ (odds ratio $=2.6), \mathrm{e} 3 / \mathrm{e} 4($ odds ratio $=3.2)$, and e4/e4 (odds ratio $=14.9$; see meta-analysis by Farrer et al., 1997). However, APOE genotype does not modify rate of decline in $\mathrm{AD}$ after the clinical diagnosis has been made (e.g., Corder et al., 1995; Growdon et al., 1996), and even progression from the preclinical stage to clinically verified $\mathrm{AD}$ is indistinguishable for carriers and non-carriers of the e 4 allele (Bäckman et al., 2003; Bunce et al., 2004a).

The absence of deleterious effects of the e4 allele on cognition in younger adults (high resource levels) and the presence of such effects in normal older adults (medium resource levels) is in good agreement with the resource modulation hypothesis. Similarly, the observation of a waning influence of APOE on cognition during the preclinical and later phases of $\mathrm{AD}$ is consistent with the hypothesis, as genetic effects on cognition are expected to decrease when resource levels are exceedingly low (see Figure 1). A study by Almeida et al. (2008) on the effects of the KIBRA gene on episodic memory constitutes another case in point. Almeida and col- 
leagues examined a sample of 312 adults aged 50-89 years. Of these, 133 were classified with mild cognitive impairment (MCI). In line with the findings reported by Papassotiropoulos et al. (2006) and Schaper et al. (2008), the KIBRA gene influenced episodic memory in the normal range of functioning, with lower scores for the CC genotype. However, the risk for MCI did not differ reliably between $\mathrm{CC}$ homozygotes and $\mathrm{T}$ carriers of the KIBRA gene, and this gene was not associated with memory performance among the MCI individuals, leading the authors to suggest that the KIBRA gene "plays all but a limited role after scores fall below a certain threshold" (Almeida et al., 2008, p. 1675). At a more general level, results from twin studies indicate that the genetic contribution to individual differences in cognitive functioning may decrease in very old age (Finkel et al., 1998). Thus, in line with the resource modulation hypothesis, there is initial evidence that the influence of common genetic polymorphisms may decrease in $\mathrm{AD}$ and in the terminal phase of the lifespan, when cognitive resources are greatly depleted.

\section{CONCLUSION AND OUTLOOK}

In this article, we propose the hypothesis that neurochemical and anatomical brain resources modulate the influence of common genetic polymorphisms on human cognition because the function relating brain resources to cognitive performance is nonlinear. We applied this hypothesis to cognitive aging, and summarized the results of an age-comparative study by Nagel et al. (2008) of COMT and BDNF gene effects on executive functioning and spatial WM, which provides initial support for our hypothesis.
To further test the prediction that brain aging magnifies genetic effects on cognition from early to late adulthood, research designs need to include groups of younger and older adults or sample individuals in a continuous fashion across the lifespan. In addition, sample sizes need to be sufficiently large to detect higher-order interactions between multiple genes and age. We also recommend that future research on aging, genetics, and cognition pays greater attention to sample differences in task-relevant resources, as such differences may predictably modulate (e.g., magnify or attenuate) the size of genetic effects. Age differences in genetic effects on human cognition are occasionally attributed to mechanisms that are difficult to test and hard to verify, such as antagonistic pleiotropy (e.g., Finch and Tanzi, 1997; Reynolds et al., 2006) or complex gene $\times$ environment interactions (e.g., Reynolds et al., 2007). Although we do not deny that these explanatory options may be valid, we invite researchers to consider resource modulation as a likely and parsimonious alternative.

\section{ACKNOWLEDGEMENTS}

This research reported here was supported by the Max Planck Society, including a grant from its innovation fund (M.FE.A.BILD0005). It was also supported by a grant from the German Federal Ministry for Research to the Berlin NeuroImaging Center (01GO0501). L.B. was supported by the Swedish Research Council (521-2007-2892) and the Swedish Brain Power. C.C. was supported by a Swiss National Foundation fellowship (No PBGE1-112883). I.N. was supported by a predoctoral fellowship of the International Max Planck Research School, The Life Course: Evolutionary and Ontogenetic Dynamics (LIFE).

\section{REFERENCES}

Alexander, D. M., Williams, L. M., Gatt, J. M., Dobson-Stone, C., Kuan, S. A., Todd, E. G., Schofield, P. R., Cooper, N. J., and Gordon, E. (2007). The contribution of apolipoprotein $\mathrm{E}$ alleles on cognitive performance and dynamic neural activity over six decades. Biol. Psychol. 75, 229-238.

Alexander, G. E., DeLong, M. R., and Strick, P. L. (1986). Parallel organization of functionally segregated circuits linking basal ganglia and cortex. Annu. Rev. Neurosci. 9, 357-381.

Almeida, O. P., Schwab, S. G., Lautenschlager, N. T., Morar, B., Greenop, K. R., Flicker, L., and Wildenauer, D. (2008). KIBRA genetic polymorphism influences episodic memory in later life, but does not increase the risk of mild cognitive impairment. J. Cell. Mol. Med. 12, 1672-1676.

Antonini, A., and Leenders, K. L. (1993). Dopamine D2 receptors in normal human brain: effect of age measured by positron emission tomography (PET) and [11C]-raclopride. Ann. N.Y. Acad. Sci. 695, 81-85.

Bäckman, L., Ginovart, N., Dixon, R. A., Wahlin, T. B., Wahlin, A., Halldin, C., and Farde, L. (2000). Age-related cognitive deficits mediated by changes in the striatal dopamine system. Am. J. Psychiatry 157, 635-637.

Bäckman, L., Jones, S., Small, B. J., Agüero-Torres, H., and Fratiglioni, L. (2003). Rate of cognitive decline in preclinical Alzheimer's disease: the role of comorbidity. J. Gerontol. B Psychol. 58, 228-236.
Bäckman, L., Nyberg, L., Lindenberger, U. Li, S. -C., and Farde, L. (2006). The correlative triad among aging, dopamine, and cognition: current status and future prospects. Neurosci. Biobehav. Rev. 30, 791-807.

Bäckman, L., and Small, B. J. (1998) Influences of cognitive support on episodic remembering: tracing the process of loss from normal aging to Alzheimer's disease. Psychol. Aging 13, 267-276.

Bäckman, L., Small, B. J., Wahlin, A. and Larsson, A. (1999). Cognitive functioning in very old age. In Handbook of Aging and Cognition, vol. 2, F. I. Craik and T. Salthouse eds (Mahwah, NJ, Erlbaum), pp. 499-558.

Baltes, P. B., and Lindenberger, U. (1997) Emergence of a powerful connection between sensory and cognitive func- tions across the adult life span: a new window to the study of cognitive aging? Psychol. Aging 12, 12-21.

Baltes, P. B., Staudinger, U. M., and Lindenberger, U. (1999). Lifespan psychology: theory and application to intellectual functioning. Annu. Rev. Psychol. 50, 471-507.

Barnett, J. H., Jones, P. B., Robbins, T. W., and Muller, U. (2007). Effects of the catechol-O-methyltransferase Val158Met polymorphism on executive function: a meta-analysis of the Wisconsin Card Sort Test in schizophrenia and healthy controls. Mol. Psychiatry 12, 502-509.

Bertolino, A., Rubino, V., Sambataro, F. Blasi, G., Latorre, V., Fazio, L., Caforio, G., Petruzzella, V., Kolachana, B., Hariri, A., MeyerLindenberg, A., Nardini, M., 
Weinberger, D. R., and Scarabino, T. (2006). Prefrontal-hippocampal coupling during memory processing is modulated by COMT val158met genotype. Biol. Psychiatry 60, 1250-1258.

Bilder, R. M., Volavka, J., Lachman, H. M., and Grace, A.A. (2004). The catecholO-methyltransferase polymorphism: relations to the tonic-phasic dopamine hypothesis and neuropsychiatric phenotypes. Neuropsychopharmacology 29, 1943-1961.

Brehmer, Y., Li, S. -C., Müller, V., von Oertzen, T., and Lindenberger, U. (2007). Memory plasticity across the lifespan: uncovering children's latent potential. Dev. Psychol. 43, 465-478.

Buckner, R.L., Raichle, M.E., Miezin,F.M., and Petersen, S. E. (1996). Functional anatomic studies of memory retrieval for auditory words and visual pictures. J. Neurosci. 16, 6219-6235.

Bunce, D., Fratiglioni, L., Small, B. J., Winblad, B., and Bäckman, L. (2004a). APOE and cognitive decline in preclinical Alzheimer's disease and non-demented aging. Neurology 63 , 816-821

Bunce, D., Kivipelto, M., and Wahlin, A. (2004b). Utilization of cognitive support in episodic free recall as a function of apolipoprotein $\mathrm{E}$ and vitamin B-12 or folate among adults aged 75 years and older. Neuropsychology 18, 362-370.

Buther, K., Plaas, C., Barnekow, A., and Kremerskothen, J. (2004). KIBRA is a novel substrate for protein kinase C-zeta. Biochem. Biophys. Res. Commun. 317, 703-707.

Cabeza, R., Dolcos, F., Prince, S. E., Rice, H. J., Weissman, D. H., and Nyberg, L. (2003). Attention-related activity during episodic memory retrieval: a cross-function fMRI study. Neuropsychologia 41, 390-399.

Corder, E. H., Saunders, A. M., Strittmatter, W. J., Schmechel, D. E., Gaskell, P. C., Rimmler, J. B., Locke, P. A., Conneally, P. M., Schmader, K. E., Tanzi, R. E., Gusella, J. F., Small, G. W., Roses, A. D., PericakVance, M. A., and Haines, J. L. (1995). Apolipoprotein E, survival in Alzheimer's disease patients, and the competing risks of death and Alzheimer's disease. Neurology 45, 1323-1328.

Courtney,S.M., Ungerleider, L. G., Keil, K., and Haxby, J.V. (1997). Transient and sustained activity in a distributed neural system for human working memory. Nature 386, 608-611.

Craik, F. I. M. (1983). On the transfer of information from temporary to permanent memory. Philos. Trans. R. Soc. Lond., B, Biol. Sci. 302, 341-359.
Deary, I. J., Whiteman, M. C., Pattie, A., Starr, J. M., Hayward, C., Wright, A. F., Carothers, A., and Whalley, L. J. (2002). Cognitive change and the apoe 4 allele. Nature 418, 932.

Deary, I. J., Whiteman, M. C., Starr, J. M., Whalley, L. J., and Fox, H. C. (2004). The impact of childhood intelligence on later life: following up the Scottish mental surveys of 1932 and 1947. J. Pers. Soc. Psychol. 86, 130-147.

de Frias, C. M., Annerbrink, K., Westberg, L., Eriksson, E., Adolfsson, R., and Nilsson, L. G. (2004).COMT gene polymorphism is associated with declarative memory in adulthood and old age. Behav. Genet. 34, 533-539.

de Frias, C. M., Annerbrink, K., Westberg, L., Eriksson, E., Adolfsson, R., and Nilsson, L. G. (2005). Catechol O-methyltransferase Val158Met polymorphism is associated with cognitive performance in nondemented adults. J. Cogn. Neurosci. 17, 1018-1025.

de Frias, C. M., Lövdén, M. Lindenberger, U., and Nilsson, L. G. (2007). Revisiting the dedifferentiation hypothesis with longitudinal multi-cohort data. Intelligence 35 , 381-392.

de Geus, E., Goldberg, T., Boomsma, D. I., Posthuma, D. (2008). Imaging the genetics of brain structure and function. Biol. Psychol. 79, 1-8.

Diamond, A. (2007). Consequences of variations in genes that affect dopamine in prefrontal cortex. Cereb. Cortex 17, 1161-1170.

Egan, M. F., Goldberg, T. E., Kolachana, B. S., Callicott, J. H., Mazzanti, C. M., Straub, R. E., Goldman, D., and Weinberger, D. R. (2001). Effect of COMT Val108/158 Met genotype on frontal lobe function and risk for schizophrenia. Proc. Natl. Acad. Sci. U.S.A. 98, 6917-6922.

Egan, M. F., Kojima, M., Callicott, J. H., Goldberg, T. E., Kolachana, B. S., Bertolino, A., Zaitsev, E., Gold, B., Goldman, D., Dean, M., Lu, B., and Weinberger, D. R. (2003). The BDNF val66met polymorphism affects activity-dependent secretion of BDNF and human memory and hippocampal function. Cell 112, 257-269.

Erixon-Lindroth, N., Farde, L., Wahlin, T. B., Sovago, J., Halldin, C., and Bäckman, L. (2005). The role of the striatal dopamine transporter in cognitive aging. Psychiatr. Res. 138, $1-12$.

Farrer, L. A., Cupples, L. A., Haines, J. L., Hyman, B. T., Kukull, W. A., Mayeaux, R., Myers, R. H., Petricak Vance, M. A., Risch, N., and van
Duijn, C. M. (1997). Effects of age, sex, and ethnicity on the association between apolipoprotein E genotype and Alzheimer's disease: a metaanalysis. J. Am. Med. Assoc. 278, 1349-1356.

Finch,C.E., and Tanzi,R.E. (1997). Genetics of aging. Science 278, 407-411.

Finkel, D., Pedersen, A. L., Plomin, R., and McClearn, G. E. (1998). Longitudinal and cross-sectional twin data on cognitive abilities in adulthood: the Swedish Adoption/Twin Study of Aging. Dev Psychol. 34, 1400-1413.

Finkel, D., Reynolds, C. A., McArdle, J. J., and Pedersen, N. L. (2005). The longitudinal relationship between processing speed and cognitive ability: genetic and environmental influences. Behav. Genet. 35, 535-549.

Friedman, N. P., Miyake, A., Young, S. E., DeFries, J. C., Corley, R. P., and Hewitt, J. K. (2008). Individual differences in executive functions are almost entirely genetic in origin J. Exp. Psychol. Gen. 137, 201-225.

Goldberg, T. E., and Weinberger, D. R. (2004). Genes and the parsing of cognitive processes. Trends Cogn. Sci. 8, 325-335.

Goldman-Rakic, P. S., Muly, E. C., III and Williams, G. V. (2000). D(1) receptors in prefrontal cells and circuits. Brain Res. Rev. 31, 295-301.

Gosso, M. F., de Geus, E., Polderman, T., Boomsma, D. I., Heutink, P., and Posthuma, D. (2008). Catechol O-methyltransferase and dopamine D2 receptor gene polymorphisms: evidence of positive heterosis and genegene interaction on working memory functioning. Eur. J. Hum. Genet. 16 , 1075-1082.

Grace, A. A., Floresco, S. B., Goto, Y., and Lodge, D. J. (2007). Regulation of firing of dopaminergic neurons and control of goal-directed behaviors. Trends Neurosci. 30, 220-227.

Growdon, J. H., Locascio, J. J., Corlin, S., Gomezsla, T., and Hyman, B. T. (1996). Apolipoprotein E genotype does not influence rates of cognitive decline in Alzheimer's disease. Neurology 47 , 444-448.

Hariri, A. R., Goldberg, T. E., Mattay, V. S., Kolachana, B. S., Callicott, J. H., Egan, M. F., and Weinberger, D. R. (2003). Brain-derived neurotrophic factor val66met polymorphism affects human memory-related hippocampal activity and predicts memory performance. J. Neurosci. 23, 6690-6694.

Harris, S. E., Wright, A. F., Hayward, C., Starr, J. M., Whalley, L. J., and Deary, I. J. (2005). The functional COMT polymorphism, Val 158 Met, is associated with logical memory and the personality trait intellect/imagination in a cohort of healthy 79-yearolds. Neurosci. Lett. 385, 1-6.

Heaton, D., Chelune, G. J., Talley, J. L., Kay, G. G., and Curtis, G. (1993). Wisconsin Card Sorting Test Manual: Revised and Expanded. Odessa, FL, Psychological Assessment Resources.

Hertzog, C., and Schaie, K. W. (1986). Stability and change in adult intelligence: 1. Analysis of longitudinal covariance structures. Psychol. Aging $1,159-171$.

Ho, B. C., Milev, P., O'Leary, D. S., Librant, A., Andreasen, N. C., and Wassink, T. H. (2006). Cognitive and magnetic resonance imaging brain morphometric correlates of brain-derived neurotrophic factor Val66Met gene polymorphism in patients with schizophrenia and healthy volunteers. Arch. Gen. Psychiatry 63, 731-740.

Ho, B. C., Wassink, T. H., O'Leary, D. S., Sheffield, V. C., and Andreasen, N. C. (2005). Catechol-O-methyl transferase Val158Met gene polymorphism in schizophrenia: working memory, frontal lobe MRI morphology and frontal cerebral blood flow. Mol. Psychiatry 10, 229, 287-298.

Huber, J. D. (2008). Diabetes, cognitive function, and the blood-brain barrier. Curr. Pharm. Des. 14, 1594-1600.

Kaasinen, V., Vilkman, H., Hietala, J., Nagren, K., Helenius, H., Olsson, H., Farde, L., and Rinne, J. (2000). Age-related dopamine D2/D3 receptor loss in extrastriatal regions of the human brain. Neurobiol. Aging 21, 683-688.

Kinsbourne, M., and Hicks, R. E. (1978). Functional cerebral space: a model for overflow, transfer and interference effects in human performance: a tutorial review. In Attention and Performance VII, J. Requin, ed. (Hillsdale, NJ, Erlbaum), pp. 345-362.

Kliegl, R., Mayr, U., and Krampe, R. T. (1994). Time-accuracy functions for determining process and person differences: an application to cognitive aging. Cognit. Psychol. 26, 134-164.

Kovas, Y., and Plomin, R. (2006). Generalist genes: implications for the cognitive sciences. Trends Cogn. Sci. 10, 198-203.

Li, S. -C. (2003). Biocultural orchestration of developmental plasticity across levels: the interplay of biology and culture in shaping the mind and behavior across the life span. Psychol. Bull. 129, 171-194.

Li,S.-C.,Lindenberger, U., and Sikström, S. (2001). Aging cognition: from neuromodulation to representation. Trends Cogn. Sci. 5, 479-486. 
Li, S. -C., and Sikström, S. (2002). Integrative neurocomputational perspectives on cognitive aging, neuromodulation, and representation. Neurosci. Biobehav. Rev. 26, 795-808.

Lord, F. M. (1980). Applications of Item Response Theory to Practical Testing Problems. Hillsdale, NJ, Erlbaum.

Malhotra, A. K., Kestler, L. J., Mazzanti, C., Bates, J. A., Goldberg, T., and Goldman, D. (2002). A functional polymorphism in the COMT gene and performance on a test of prefrontal cognition. Am. J. Psychiatry 159, 652-654.

Mattay, V. S., Fera, F., Tessitore, A., Hariri, A. R., Berman, K. F., Das, S., Meyer-Lindenberg, A., Goldberg, T. E., Callicott, J. H., and Weinberger, D. R. (2006). Neurophysiological correlates of age-related changes in working memory capacity. Neurosci. Lett. 392, 32-37.

Mattay, V. S., Goldberg, T. E., Fera, F., Hariri, A. R., Tessitore, A., Egan, M. F., Kolachana, B., Callicott, J. H., and Weinberger, D. R. (2003). Catechol O-methyltransferase val158-met genotype and individual variation in the brain response to amphetamine. Proc. Natl. Acad. Sci. U.S.A. 100, 6186-6191.

Mattay, V.S., Goldberg, T.E., Sambataro, F., and Weinberger, D. R. (2008). Neurobiology of cognitive aging: insights from imaging genetics. Biol. Psychol. 79, 9-22.

McClearn, G.E. (2006). Contextual genetics. Trends Genet. 22, 314-319.

McClearn, G. E., Johansson, B., Berg, S., Pedersen, N. L., Ahern, F., Petrill, S. A., and Plomin, R. (1997). Substantial genetic influence on cognitive abilities in twins 80 or more years old. Science 276, 1560-1563.

McGue, M., Bouchard, T. J., Jr., Iacono, W. G., and Lykken, D. T. (1993). In Nature, Nurture, and Psychology, R. Plomin and G. E. McClearn, eds (Washington, DC, American Psychological Association), pp. 59-76.

Mellenbergh, G. J. (1994). Generalized linear item response theory. Psychol. Bull. 115, 300-307.

Meyer-Lindenberg, A., Nichols, T., Callicott, J. H., Ding, J., Kolachana, B., Buckholtz, J., Mattay, V. S., Egan, M., and Weinberger, D. R. (2006). Impact of complex genetic variation in COMT on human brain function. Mol. Psychiatry 11, 867-877, 797.

Meyer-Lindenberg, A., Straub, R. E., Lipska, B. K., Verchinski, B. A., Goldberg, T., Callicott,J.H.,Egan, M. F., Huffaker, S. S., Mattay, V. S., Kolachana, B., Kleinman, J. E., and Weinberger, D. R. (2007). Genetic evidence implicating DARPP-32 in human frontostriatal structure, function, and cognition. J. Clin. Invest. 117, 672-682.

Miller, E. K., and Cohen, J. D. (2001). An integrative theory of prefrontal cortex function. Annu. Rev. Neurosci. 24, 167-202.

Miyajima, F., Ollier, W., Mayes, A., Jackson, A., Thacker, N., Rabbitt, P., Pendleton, N., Horan, M., and Payton, A. (2008). Brain-derived neurotrophic factor polymorphism Val66Met influences cognitive ability in the elderly. Genes Brain Behav. 7, 411-417.

Montague, P. R., Hyman, S. E., and Cohen, J. D. (2004). Computational roles for dopamine in behavioural control. Nature 431, 760-767.

Morley, J. E. (2008). Diabetes and aging: epidemiologic overview. Clin. Geriatr. Med. 24, 395-405.

Nagel, I. E., Chicherio, C., Li, S. -C., von Oertzen, T., Sander, T., Villringer, A., Heekeren, H. R., Bäckman, L., and Lindenberger, U. (2008). Human aging magnifies genetic effects on executive functioning and working memory. Front. Hum. Neurosci. 2, 1. doi: 10.3389/neuro.09.001.2008.

Naghavi, H. R., and Nyberg, L. (2005). Common fronto-parietal activity in attention, memory, and consciousness: shared demands on cognition? Conscious. Cogn. 14, 390-425.

Narita, M., Aoki, K., Takagi, M., Yajima, Y., and Suzuki, T. (2003). Implication of brain-derived neurotrophic factor in the release of dopamine and dopamine-related behaviors induced by methamphetamine. Neuroscience 119, 767-775.

Naveh-Benjamin,M., Craik, F.I.M., and Li, B. -S. (2002).Age-related differences in cued recall: effects of support at encoding and retrieval. Aging Neuropsychol. Cogn. 9, 276-287.

Norman, D. A., and Bobrow, D. G. (1975). On data-limited and resource-limited processes. Cogn. Psychol. 7, 44-64.

Olson, I. R., Moore, K. S., Stark, M., and Chatterjee, A. (2006). Visual working memory is impaired when the medial temporal lobe is damaged. J. Cogn. Neurosci. 18, 1087-1097.

Papassotiropoulos, A., Stephan, D. A., Huentelman, M. J., Hoerndli, F. J., Craig, D.W.,Pearson,J.V.,Huynh, K. D., Brunner, F., Corneveaux, J., Osborne, D., Wollmer, M. A., Aerni, A., Coluccia, D., Hanngi, J., Mondadori, C. R., Buchmann, A., Reiman, E. M., Caselli, R. J., Henke, K., and de Quervain, D. J. (2006). Common KIBRA alleles are associated with human memory performance. Science 314, 475-478.
Pezawas, L., Verchinski, B. A., Mattay, V. S., Callicott, J. H., Kolachana, B. S., Straub, R. E., Egan, M. F., MeyerLindenberg, A., and Weinberger, D. R. (2004). The brain-derived neurotrophic factor val66met polymorphism and variation in human cortical morphology. J. Neurosci. 24, 10099-10102.

Piekema, C., Fernandez, G., Postma, A., Hendriks, M. P., Wester, A. J., and Kessels, R. P. (2007). Spatial and nonspatial contextual working memory in patients with diencephalic or hippocampal dysfunction. Brain Res. 1172, 103-109.

Posner, M. I., Rothbart, M. K., and Sheese, B. E. (2007). Attention genes Dev. Sci. 10, 24-29.

Raz, N., Dahle, C. L., Rodrigue, K. M., Kennedy, K. M., Land, S. J., and Jacobs, B. S. (2008a). Brain-derived neurotrophic factor Val66Met and blood glucose: a synergistic effect on memory. Front. Hum. Neurosci. 2 12.doi: 10.3389/neuro.09.012.2008.

Raz, N., Lindenberger, U., Ghisletta, P., Rodrigue, K. M., Kennedy, K. M., and Acker, J. D. (2008b). Neuroanatomical correlates of fluid intelligence in healthy adults and persons with vascular risk factors. Cereb. Cortex 18 718-726.

Raz, N., Lindenberger, U., Rodrigue, K. M., Kennedy, K. M., Head, D., Williamson, A., Dahle, C., Gerstorf, D., and Acker, J. D. (2005). Regional brain changes in aging healthy adults: general trends, individual differences and modifiers. Cereb. Cortex 15, 1676-1689.

Raz, N., Rodrigue, K. M., Kennedy, K. M., and Land, S. (in press). Genetic and vascular modifiers of age-sensitive cognitive skills: effects of COMT, BDNF, ApoE, and hypertension. Neuropsychology.

Reynolds, C. A., Gatz, M., and Pedersen, N. L. (2007). Genotypeenvironment interactions: cognitive aging and social factors. Twin Res. Hum. Genet. 10, 241-254.

Reynolds, C. A., Prince, J. A., Feuk, L., Brookes, A. J., Gatz, M., and Pedersen, N. L. (2006). Longitudinal memory performance during normal aging: twin association models of APOE and other Alzheimer candidate genes. Behav. Genet. 36, 185-194.

Rolandsson, O., Bäckström, A., Eriksson, S., Hallmans, G., and Nilsson, L. -G. (2008). Increased glucose levels are associated with episodic memory in non-diabetic women. Diabetes 57, 440-443.

Rybakowski, J. K., Borkowska, A., Czerski, P. M., Skibinska, M., and Hauser, J. (2003). Polymorphism of the brain-derived neurotrophic factor gene and performance on a cognitive prefrontal test in bipolar patients. Bipolar Disord. 5, 468-472.

Rypma, B., and D'Esposito, M. (2000). Isolating the neural mechanisms of age-related changes in human working memory. Nat. Neurosci. 3, 509-515.

Savitz, J., Solms, M., and Ramesar, R. (2006). The molecular genetics of cognition: dopamine, COMT and BDNF. Genes Brain Behav. 5, 311-328.

Schaper, K., Kolsch, H., Popp, J., Wagner, M., and Jessen, F. (2008). KIBRA gene variants are associated with episodic memory in healthy elderly. Neurobiol. Aging 29, 1123-1125.

Schultz, M. R., Lyons, M. J., Franz, C. E., Grant,M.D., Boake, C. Jacobson, K. C., Xian, H., Schellenberg, G. D., Eisen, S. A., and Kremen, W.S. (2008). Apolipoprotein E genotype and memory in the sixth decade of life. Neurology 70, 1771-1777.

Seamans, J. K., and Yang, C. R. (2004). The principal features and mechanisms of dopamine modulation in the prefrontal cortex. Prog. Neurobiol. 74, 1-57.

Shing, Y. L., Werkle-Bergner, M., Li, S. -C., and Lindenberger, U. (2008). Associative and strategic components of episodic memory: a life-span dissociation. J. Exp. Psychol. Gen. 137, 495-513.

Small, B. J., Rosnick, C. B., Fratiglioni, L., and Bäckman, L. (2004). Apolipoprotein $\mathrm{E}$ and cognitive performance: a meta-analysis. Psychol. Aging 19, 592-600.

Smolka, M. N., Buhler, M., Schumann, G., Klein, S., Hu, X. Z., Moayer, M., Zimmer, A., Wrase, J., Flor, H. Mann, K., Braus, D. F., Goldman, D., and Heinz, A. (2007). Gene-gene effects on central processing of aversive stimuli. Mol. Psychiatry 12, 307-317.

Starr, J. M., Fox, H., Harris, S. E., Deary, I. J., and Whalley, L. J. (2007). COMT genotype and cognitive ability: a longitudinal aging study. Neurosci. Lett. 421, 57-61.

Suhara, T., Fukuda, H., Inoue, O., Itoh, T., Suzuki, K., Yamasaki, T., and Tateno, Y. (1991).Age-related changes in human D1 dopamine receptors measured by positron emission tomography. Psychopharmacology 103, 41-45.

Takahashi, H., Kato, M., Hayashi, M., Okubo, Y., Takano, A., Ito, H., and Suhara, T. (2007). Memory and frontal lobe functions; possible relations with dopamine D2 receptors in the hippocampus. Neuroimage 34, 1643-1649.

Tan, H. Y., Chen, Q., Sust, S., Buckholtz, J. W., Meyers, J. D., Egan, M. F., Mattay, V. S., MeyerLindenberg, A., Weinberger, D. R., 
and Callicott, J. H. (2007). Epistasis between catechol-O-methyltransferase and type II metabotropic glutamate receptor 3 genes on working memory brain function. Proc. Natl. Acad. Sci. U.S.A. 104, 12536-12541.

Tsai, S. J., Hong, C. J., Liao, D. L., Lai, I. C., and Liou, Y. J. (2004). Association study of a functional catechol-O-methyltransferase genetic polymorphism with age of onset, $\operatorname{cog}$ nitive function, symptomatology and prognosis in chronic schizophrenia. Neuropsychobiology 49, 196-200.

Tsai, S. J., Yu, Y. W., Chen, T. J., Chen, J. Y., Liou, Y. J., Chen, M. C., and Hong, C. J. (2003). Association study of a functional catechol-O-methyltransferasegene polymorphism and cognitive function in healthy females. Neurosci. Lett. 338, 123-126.

Vijayraghavan, S., Wang, M., Birnbaum, S. G., Williams, G. V., and Arnsten, A. F. (2007). Inverted-U dopamine D1 receptor actions on prefrontal neurons engaged in working memory. Nat. Neurosci. 10, 376-384.

Volkow, N. D., Wang, G. J., Fowler, J. S., Ding,Y.S., Gur, R.C., Gatley, J., Logan, J., Moberg, P. J., Hitzemann, R., Smith, G., and Pappas, N. (1998). Parallel loss of presynaptic and postsynaptic dopamine markers in normal aging. Ann. Neurol. 44, 143-147.

West, R. L. (1996). An application of prefrontal cortex function theory to cognitive aging. Psychol. Bull. 120, 272-292.
Xu, X., Mill, J., Zhou, K., Brookes, K., Chen, C. K., and Asherson, P. (2007). Family-based association study between brain-derived neurotrophic factor gene polymorphisms and attention deficit hyperactivity disorder in UK and Taiwanese samples. Am. J. Med. Genet. B Neuropsychiatr. Genet. 144, 83-86.

Yacubian, J., Sommer, T., Schroeder, K., Glascher,J., Kalisch, R., Leuenberger, B. Braus, D. F., and Buchel, C. (2007) Gene-gene interaction associated with neural reward sensitivity. Proc. Natl. Acad. Sci. U.S.A. 104 8125-8130.

Conflict of Interest Statement: The authors declare that this research was conducted without any commercial or financial relationships that could be construed as a potential conflict of interest.

Received: 05 October 2008; accepted: 11 November 2008; published: 15 December 2008.

Citation: Front. Neurosci. (2008) 2, 2:234 244. doi: 10.3389/neuro.01.039.2008

Copyright: ( 2008 Lindenberger, Nagel, Chicherio, Li, Heekeren and Bäckman. This is an open-access article subject to an exclusive license agreement between the authors and the Frontiers Research Foundation, which permits unrestricted use, distribution, and reproduction in any medium, provided the original authors and source are credited. 